\title{
Cefepime Restriction Improves Gram-Negative Overall Resistance Patterns in Neonatal Intensive Care Unit
}

\author{
Orlei Ribeiro de Araujo, Dafne Cardoso Bourguignon da Silva, Ana Regina Diegues, Ronaldo Arkader, Eloíza Aparecida \\ Ferreira Cabral, Marta Rodriguez Afonso, Maria Eduarda Louzada and Andréa de Cássia Stéfano Albertoni \\ Hospital e Maternidade Santa Marina; São Paulo, SP, Brasil
}

\begin{abstract}
Antibiotic restriction can be useful in maintaining bacterial susceptibility. The objective of this study was verify if restriction of cefepime, the most frequently used cephalosporin in our neonatal intensive care unit (NICU), would ameliorate broad-spectrum susceptibility of Gram-negative isolates. Nine hundred and ninety-five premature and term newborns were divided into 3 cohorts, according to the prevalence of cefepime use in the unit: Group 1 $(n=396)$ comprised patients admitted from January 2002 to December 2003, period in which cefepime was the most used broad-spectrum antibiotic. Patients in Group $2(n=349)$ were admitted when piperacillin/tazobactam replaced cefepime (January to December 2004) and in Group $3(n=250)$ when cefepime was reintroduced (January to September 2005). Meropenem was the alternative third-line antibiotic for all groups. Multiresistance was defined as resistance to 2 or more unrelated antibiotics, including necessarily a third or fourth generation cephalosporin, piperacillin/tazobactam or meropenem. Statistics involved Kruskal-Wallis, Mann-Whitney and logrank tests, Kaplan-Meier analysis. Groups were comparable in length of stay, time of mechanical ventilation, gestational age and birth weight. Ninety-eight Gram-negative isolates were analyzed. Patients were more likely to remain free of multiresistant isolates by Kaplan-Meier analysis in Group 2 when compared to Group 1 (p=0.017) and Group $3(p=0.003)$. There was also a significant difference in meropenem resistance rates. Cefepime has a greater propensity to select multiresistant Gram-negative pathogens than piperacillin/tazobactam and should not be used extensively in neonatal intensive care.
\end{abstract}

Key-Words: Drug resistance, infection control, cefepime, bacterial.

Although many Gram-negative bacteria can naturally produce enzymes that destroy $\beta$-lactam antibiotics $(\beta$ lactamases), bacterial resistance can be considered, at most, a biological response to selective pressure. The widespread use of expanded spectrum $\beta$-lactam antibiotics (like thirdgeneration cephalosporins) for treatment of nosocomial infections has led to emergence of $\beta$-lactamases, capable to efficiently hydrolyse these compounds (the so called extended spectrum $\beta$-lactamases, ESBLs) [1]. In neonatal intensive care units, infection by multidrug-resistant Gramnegative microorganisms is a threat for survival of premature and term newborns, since the therapeutic choices are limited for this group of patients and susceptibility of isolates in neonatal septicemia to the most commonly used antibiotics is decreasing around the world [2-4]. Measures of control, like correct training of the health team and standard contact precautions have been only partially successful on diminishing the emergence of multiresistant pathogens [5]. Since emergence of resistance is a characteristic of the evolution of bacteria, it has been claimed as unavoidable, however, its dissemination can be delayed [6]. As resistance is related to selective pressure exerted by the use of

Received on 11 September 2006; revised 23 March 2007.

Address for correspondence: Dr. Orlei Ribeiro de Araujo. Alameda Rio Claro, 95 / 74 - Bela Vista - São Paulo, SP, Zip code: 01332-010. Phone: 50131263 / 50131435 Fax 55639331. E-mail: orlei@uol.com.br. Financial support: From the institution itself. This work did not receive any kind of support from the pharmaceutical industry.

The Brazilian Journal of Infectious Diseases

2007;11(2):277-280. (C) 2007 by The Brazilian Journal of Infectious Diseases and Contexto Publishing. All rights reserved. antimicrobial agents, withdrawal of this pressure can theoretically revert specific resistance. Intensive antibiotic control has been demonstrated to be associated to higher prevalence of bacterial susceptibility, which decreases when control is relaxed [7].

Cefepime, proposed to be more stable to $\beta$-lactamase hydrolysis [8], has been used in our neonatal intensive care unit since 2001. In January 2002 we started a surveillance program for prevention and control of infection by multiresistant bacteria. At the end of 2003, with ominous third and fourth-generation cephalosporins and imipenem/ meropenem resistance rates among Gram-negative bacteria, we decided to suppress use of cefepime for 1 year, in order to observe if this measure would reduce the risk of isolation of multiresistant Gram-negative bacteria.

\section{Materials and Methods}

This study was performed in the 15-bed NICU of a tertiarycare hospital in São Paulo, Brazil, after approval of Institutional Ethics Committee. A total of 995 premature and term newborns were admitted in the NICU between January 2002 and September 2005. All positive cultures were recorded in a database, and the same was done for number of days of each antibiotic used. Cultures were obtained following clinical indications. For analysis, patients were divided in three cohorts, according to restriction to cefepime use in the unit: from January 2002 to December 2003 (Group 1, n=396) cefepime was the antibiotic of choice when a second-line antimicrobial regimen for Gram-negative coverage was needed. From January to December 2004 (Group 2, n=349), piperacillintazobactam was the second-line regimen, and from January to September 2005 (Group 3, n=250) cefepime was 
reintroduced. Meropenem was the third-line choice for all groups. As initial empirical therapy, the association of penicillin with amikacin (or gentamicin) was the first-line regimen. No other cephalosporin was significantly used in any group.

Clinical data prospectively collected at NICU discharge for our surveillance program included demographics, number of days in the unit, days in mechanical ventilation and parenteral nutrition, and use of central venous catheters. Differences among groups, concerning these data and days of use of antibiotics, were analyzed with Kruskal-Wallis test, followed by the Mann-Whitney U test, considering groups as independent and unpaired samples. Kaplan-Meier analysis and logrank tests were performed, considering "survival" as remaining free of multiresistant Gram-negative isolates, by cohort, during the period of hospitalization in NICU $[9,10]$. A p value of $<0.05$ was considered as significant.

Antibiotic susceptibility testing was made by standard disk diffusion and interpretation of MICs (minimal inhibition concentrations) was performed as recommended by the National Committee for Clinical Laboratory Standards [11]. Multiresistance was defined as resistance to two unrelated antibiotics, including necessarily a third or fourth generation cephalosporin, or piperacillin/tazobactam, or meropenem. The standard measures for infection control (like use of gloves and gowns, washing hands, etc.) were the same during the period of study.

\section{Results}

No differences were observed for invasive mechanical ventilation, days of parenteral nutrition, length of stay in intensive care, gestational age or birth weight. Cefepime was the most frequently used second-line antimicrobial agent in Groups 1 and 3, and piperacillin/tazobactam in Group 2. There was no significant difference in meropenem use for the three groups (Table 1).

A total of 98 Gram-negative isolates were considered suitable for analysis (Table 2), after excluding multiple isolates for the same patient. Klebsiella pneumoniae and Pseudomonas aeruginosa were the pathogens most frequently isolated. The number of Gram-negative isolates was similar among groups ( $\mathrm{p}=0.29)$, and the same was observed for Gram-positive ( $\mathrm{p}=0.54$ ) and Candida species $(\mathrm{p}=0.93)$. Isolation of multiresistant Gram-negative pathogens was lower in Group 2, in which cefepime was not the secondline antimicrobial agent used for suspected or confirmed Gram-negative infection in comparison to Group 1 ( $p$ logrank test $=0.017)$ and Group $3(\mathrm{p}=0.003)$. Resistance rates were similar between Groups 1 and 3 ( $\mathrm{p}=0.33$ ). Figure 1 shows the Kaplan-Meier curves for the probabilities of remaining free of multiresistant isolates, clearly similar between Groups 1 and 3. Patients in Group 2 were more likely to remain free of these isolates during NICU hospitalization.

Among multiresistant isolates in Group 1, 8(73\%) were resistant to ceftazidime, 2(18\%) were resistant to cefepime and 2 (18\%) to piperacillin/tazobactam. For the 2 multiresistant isolates in Group 2, both were resistant to ceftazidime, and 1 resistant to piperacillin/tazobactam. In Group 3, 8 (80\%) were resistant to ceftazidime, 4 (40\%) were resistant to cefepime and $4(40 \%)$ to piperacillin/tazobactam. There were 5 meropenem-resistant isolates among Gram-negatives in Group 1, 3 in Group 3, and none in Group 2 ( $\mathrm{p}=0.04$ ).

\section{Discussion}

Since the first description of a plasmid-mediated $\beta$ lactamase in 1965, in a strain of $E$. coli from a patient in Greece, more than 180 types have been described, some of them with greater activity against extended-spectrum $\beta$-lactam antibiotics [1]. The carbapenemases, active against carbapenems, are particular worrisome, since these antibiotics frequently are the last safe and reliable alternative for multidrug-resistant Gram-negative bacteria. Exposure to broad-spectrum cephalosporin has been demonstrated to be a strong predictor for the emergence of resistant Enterobacter [12], and a risk for isolation of Klebsiella pneumoniae resistant to broad-spectrum cephalosporins and carbapenems (odds ratio 4.1) [13]. The mechanism of resistance is increased $\beta$-lactamase production [14]. Mutants that produce $\beta$ lactamase copiously may be selected during cephalosporin or ureidopenicillin therapy [15]. It has been said that cefepime has lower propensity to select resistant mutants when compared to other cephalosporins, but it has also been demonstrated that it easily selects resistant strains of Enterobacter cloacae in vitro [16]. Our findings suggest that piperacillin/tazobactam provides a less intense selective pressure for resistant strains than cefepime does.

Intensive care environment can be considered as an ecological unit, with a fragile equilibrium between microbes and the hosts they colonize. The emergence of multidrugresistance is like an ecological disaster, and "ecological' measures (like reducing the selective pressure of some antibiotics on the whole population of patients) can be an interesting approach. The study of Bradley et al.

Figure 1. Kaplan-Meier analysis shows higher probabilities (vertical axis) of remaining free of multiresistant isolates in Group 2. Horizontal axis displays the days of hospitalization in NICU.

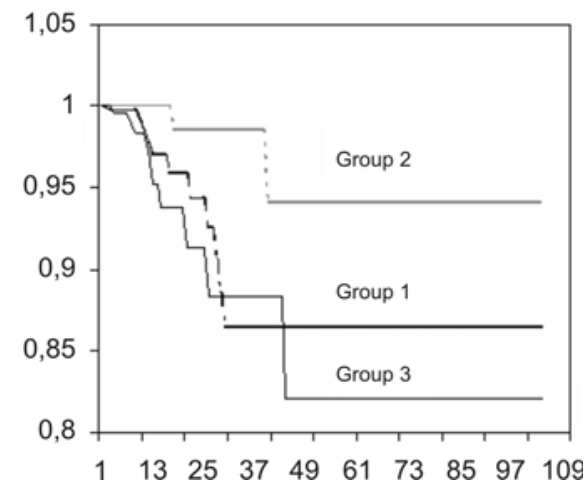


Table 1. Characteristics of groups

\begin{tabular}{|c|c|c|c|c|}
\hline & $\begin{array}{l}\text { Group } 1(2002 / 3) \\
\qquad(n=396)\end{array}$ & $\begin{array}{c}\text { Group } 2(2004) \\
\quad(n=349)\end{array}$ & $\begin{array}{l}\text { Group } 3(2005) \\
\quad(n=250)\end{array}$ & Pvalues \\
\hline Birth Weight & $2.608 \pm 0.748$ & $2.633 \pm 0.730$ & $2.564 \pm 0.830$ & 0.48 \\
\hline (mean, SD, range) & $(0.660-4.560)$ & $(0.845-4.315)$ & $(0.630-4.950)$ & \\
\hline Gestational age (mean) & 36.18 & 36.24 & 36.07 & 0.85 \\
\hline Days in intensive care* & 134 & 136 & 147 & 0.88 \\
\hline $\begin{array}{l}\text { Days of invasive } \\
\text { mechanical ventilation* }\end{array}$ & 207.9 & 163.8 & 193.1 & 0.85 \\
\hline Days of TPN* & 146.1 & 113.0 & 127.2 & 0.23 \\
\hline Central venous catheters ${ }^{\S}$ & 0.4 & 0.39 & 0.35 & 0.85 \\
\hline Penicillin + amikacin use* & 398 & 412 & 419 & 0.38 \\
\hline Cefepime use* & 118.4 & 6 & 101.2 & $\begin{array}{l}\text { Group } 1 \text { to } 2: \mathrm{p}<0.0001 \\
\text { Group } 2 \text { to } 3: \mathrm{p}<0.0001 \\
\text { Group } 1 \text { to } 3: \mathrm{p}=0.49\end{array}$ \\
\hline Piperacillin/Tazobactam use * & 40.1 & 169.6 & 36.6 & $\begin{array}{l}\text { Group } 1 \text { to } 2: \mathrm{p}<0.0001 \\
\text { Group } 2 \text { to } 3: \mathrm{p}<0.0001 \\
\text { Group } 1 \text { to } 3: \mathrm{p}=0.66\end{array}$ \\
\hline Meropenem use* & 79.2 & 85.3 & 55.2 & $\begin{array}{l}\text { Group } 1 \text { to } 2: \mathrm{p}=0.76 \\
\text { Group } 2 \text { to } 3: \mathrm{p}=0.20 \\
\text { Group } 1 \text { to } 3: \mathrm{p}=0.29\end{array}$ \\
\hline
\end{tabular}

SD=standard deviation; TPN=total parenteral nutrition; *Days per 100 patients; §Number per 100 patients.

Table 2. Isolates in cultures and resistance patterns

\begin{tabular}{|c|c|c|c|c|c|c|c|}
\hline & \multicolumn{2}{|c|}{ 2002/2003 Group (1) } & \multicolumn{2}{|c|}{2004 Group (2) } & \multicolumn{2}{|c|}{2005 Group (3) } & \multirow[t]{2}{*}{$\mathbf{P}$} \\
\hline & Isolates & $\begin{array}{c}\text { Gram-neg. } \\
\text { Multiresistant } \\
\text { isolates }\end{array}$ & Isolates & $\begin{array}{c}\text { Gram-neg. } \\
\text { Multiresistant } \\
\text { isolates }\end{array}$ & Isolates & $\begin{array}{c}\text { Gram-neg. } \\
\text { Multiresistant } \\
\text { isolates }\end{array}$ & \\
\hline Klebsiella pneumoniae & 6 & 1 & 16 & - & 14 & 7 & \\
\hline Pseudomonas aeruginosa & 8 & 1 & 9 & & 10 & 4 & \\
\hline Enterobacter cloaceae & 7 & 3 & 3 & 2 & 3 & - & \\
\hline Acinetobacter baumanii & 2 & 1 & 2 & - & 3 & 1 & \\
\hline Acinetobacter calcoaceticus & 2 & - & - & - & - & & \\
\hline E.coli & 2 & - & - & & - & - & \\
\hline Klebsiella oxytoca & 2 & 1 & 1 & - & - & - & \\
\hline Burkholderia cepacia & 1 & - & - & & - & & \\
\hline Stenotrophomonas maltophilia & 4 & 4 & - & - & - & & \\
\hline Serratiamarcescens & - & - & - & - & 1 & - & \\
\hline Haemophilus spp & & & 1 & 0 & - & - & \\
\hline Flavimonas oryzihabitans & 1 & - & - & - & - & - & \\
\hline $\begin{array}{l}\text { Gram-negative isolates } \\
\text { (total,\%) }\end{array}$ & $\begin{array}{c}35 \\
(66.0 \%)\end{array}$ & $\begin{array}{c}11 \\
(31.1 \%)\end{array}$ & $\begin{array}{c}32 \\
(65.3 \%)\end{array}$ & $\begin{array}{c}2 \\
(4.0 \%)\end{array}$ & $\begin{array}{c}31 \\
(67.3 \%)\end{array}$ & $\begin{array}{c}10 \\
(32.3 \%)\end{array}$ & 0.29 \\
\hline Source of & \multicolumn{2}{|c|}{ Blood: 12(34.2\%) } & \multicolumn{2}{|c|}{ Blood: 16(50\%) } & \multicolumn{2}{|c|}{ Blood: 2(6.4\%) } & \\
\hline Gram-negative isolate & \multicolumn{2}{|c|}{$\begin{array}{l}\text { Catheter tip: } 2(3.7 \%) \\
\text { other: } 14(40 \%)\end{array}$} & \multicolumn{2}{|c|}{$\begin{array}{l}\text { Catheter tip: 3(9.3\%) } \\
\text { other: } 4(12.5 \%)\end{array}$} & \multicolumn{2}{|c|}{$\begin{array}{l}\text { Catheter tip: } 2(6.5 \%) \\
\text { other: } 9(29.0 \%)\end{array}$} & \\
\hline Gram-positive isolates & $15(28.3)$ & - & $15(30.6 \%)$ & - & $13(28.3 \%)$ & & 0.54 \\
\hline Candida species & $3(5.6 \%)$ & - & $2(4.1 \%)$ & & $2(4.3 \%)$ & & 0.93 \\
\hline Total of isolates & 53 & & 49 & & 46 & & \\
\hline
\end{tabular}


demonstrated clearly that replacing ceftazidime with piperacillin/tazobactam for first-line treatment of febrile neutropenic patients in a haematological unit was related to a profound reduction in the risk of acquiring glycopeptideresistant Enterococcus ssp. (GRE). Reintroduction of ceftazidime in the unit led to a rise in the acquisition of GRE, implying causality [17]. This occurred probably because of ecological effects on the gut flora, also exposed and which is a reservoir of opportunist agents $[18,19]$. Another report by Rahal and co-workers showed that restriction of ceftazidime or all third-generation cephalosporins has resulted in hospitalwide reduction in cephalosporin-resistant Klebsiella infection and colonization, and overall reduction in multiresistant pathogens within 1 year [20]. These authors remark that dissemination of resistance genes by plasmids or transposon transfer leads to policlonal populations of resistant pathogens, and antibiotic class restriction alone is not able to eliminate plasmid-mediated resistance, playing a complementary role. This kind of restriction/reintroduction study was not available for cefepime. Our study demonstrates that the extensive use of this antibiotic was related to higher rates of resistance to broad-spectrum cephalosporins and meropenem. Although the small number of isolates, there was a clear rise in the resistance rates after cefepime reintroduction in the unit. We think that cefepime is invaluable and life-saving for the treatment of severe infections, but should not be used extensively in neonatal intensive care context.

\section{References}

1. Turner J.P. Extended -spectrum b-lactamases. Clin Infect Dis 2005;41(4):S273-5.

2. Agnihotri N., Kaistha N., Gupta V. Antimicrobial susceptibility of isolates from neonatal septicemia. Jpn J Infect Dis 2004;57:273-5.

3. Szabó D., Filetóth Z., Szentandrássy J., et al. Molecular epidemiology of a cluster of cases due to Klebsiella pneumoniae producing SHV-5 extended-spectrum $\beta$-lactamase in the premature intensive care unit of a Hungarian hospital. J Clin Microbiol 1999;37(12):4167-9.

4. Lee N.C., Chen S.J., Tang R.B., Hwang B.T. Neonatal bacteremia in a neonatal intensive care unit: analysis of causative organisms and antimicrobial susceptibility. J Chin Med Assoc. 2004;67(1):15-20.
5. Calil R., Marba S.T., von Nowakonski A., Tresoldi A.T. Reduction in colonization and nosocomial infection by multiresistant bacteria in a neonatal unit after institution of educational measures and restriction in the use of cephalosporins. Am J Infect Control 2001;29(3):133-8.

6. Courvalin P. Antimicrobial drug resistance: Prediction is very difficult, specially about the future. Emerg Infect Dis 2005;11(10):1503-6.

7. McGowan J.E. Do intensive hospital antibiotic control programs prevent the spread of antibiotic resistance? Infect Control Hosp Epidemiol 1994;15(7):478-83.

8. Goldstein F.W. Cephalosporinase induction and cephalosporin resistance: a longstanding misinterpretation. Clin Microbiol Infect 2002:8(12):823-5.

9. Bland J.M., Altman D.G. Survival probabilities (the Kaplan-Meier method). BMJ 1998;317:1572-3.

10. Bland J.M., Altman D.G. The logrank test. BMJ 2004;328:1073.

11. NCCLS. Performance standards antimicrobial susceptibility testing. Document M100-S11. NCCLS, Wayne (PA), 2001.

12. Kaye K.S., Cosgrove S., Harris A., Eliopoulos G., Carmeli Y.Risk factors for emergence of resistance to broad spectrum cephalosporins among Enterobacter spp. Antimicrob Agents Chemoter 2001;45(9):2628-30.

13. Kwak Y.G., Choi S., Choo E.J., Chung J.W., Jeong J., Kim N.J, et al. Risk factors for the acquisition of carbapenem-resistant Klebsiella pneumoniae among hospitalized patients. Microb Drug Resist 2005;11(2):165-9.

14. Jacobson K.L., Cohen S.H., Inciardi.F., et al. The relationship between antecedent antibiotic use and resistance to extendedspectrum cephalosporins in group I beta-lactamase-producing organisms Clin Infect Dis 1995;21(5):1107-13.

15. Yang Y.J., Livermore D.M. Chromosomal beta-lactamase expression and resistance to beta-lactam antibiotics in Proteus vulgaris and Morganella morganii. Antimicrob Agents Chemother 1988;32(9):1385-91

16. Fung-Tomc J.C., Gradelski E., Huczko E., et al. Differences in the resistant variants of Enterobacter cloacae selected by extended-spectrum cephalosporins. Antimicrob Agents Chemother 1996;40(5):1289-93.

17. Bradley S.J., Wilson A.L., Allen M.C., et al. The control of hyperendemic glycopeptide-resistant Enterococcus spp. on a haematology unit by changing antibiotic usage. J Antimicrob Chemother 1999;43(2):261-6.

18. Livermore D.M. Minimising antibiotic resistance. Lancet Infect Dis 2005; $5(7): 450-9$.

19. Rice L.B., Hutton-Thomas R., Lakticova V., et al. Beta-lactam antibiotics and gastrointestinal colonization with vancomycinresistant enterococci. J Infect Dis 2004;189(6):1113-8

20. Rahal J.J., Urban C., Horn D., et al. Class restriction of cephalosporin use to control total cephalosporin resistance in nosocomial Klebsiella. JAMA 1998;280(14):1233-7. 